\title{
Urbanismo y género: del informe de impacto de género al principio de igualdad de trato como inspirador de la nueva concepción del desarrollo urbano
}

\author{
Urbanism and gender: from the gender impact report to the \\ principle of equal treatment as an inspiration for the new \\ conception of urban development
}

\author{
Esther Rando Burgos \\ Universidad de Málaga (España) \\ ORCID: https://orcid.org/0000-0003-4832-3610 \\ erando@uma.es
}

\section{NOTA BIOGRÁFICA}

Doctora en Derecho por la Universidad de Málaga. Licenciada en Derecho y Licenciada en Ciencias del Trabajo por la Universidad de Málaga. Diplomada en Ordenación del Territorio y Máster en Regulación Económica y Territorial: especialidad Urbanismo, Ordenación del Territorio y Medio Ambiente. Profesora de Derecho Administrativo de la Universidad de Málaga. Sus líneas de investigación se centran en el ámbito del urbanismo y la ordenación del territorio, así como en la jurisdicción contencioso-administrativa.

\section{RESUMEN}

El avance de las políticas urbanas en el marco del derecho a la ciudad y la paulatina inclusión del principio de desarrollo territorial y urbano sostenible, lleva a que cada vez estén más presentes aspectos como la perspectiva de género, la sostenibilidad, la cohesión social o la participación, en suma, la búsqueda de ciudades más inclusivas, más humanas y más habitables. En no demasiado tiempo, se ha pasado de tratar de garantizar el cumplimiento de determinados aspectos en el planeamiento a través de los correspondientes informes, trámite formal desde el punto de vista procedimental, a la inclusión de criterios en los nuevos modelos de desarrollo territorial y urbano con la incorporación de medidas concretas dirigidas a su efectividad. El trabajo se centra por un lado en analizar cuándo es exigible el informe de impacto de género a la luz de la reciente jurisprudencia del Tribunal Supremo y por otro la novedad que supone el expreso reconocimiento en sede jurisdiccional del derecho a la ciudad y el principio de igualdad de trato, inspirador de la nueva concepción del desarrollo urbano y territorial sostenible, así como su paulatina inclusión en los marcos legislativos autonómicos.

\section{PALABRAS CLAVES}

Urbanismo; principio de igualdad de trato; derecho a la ciudad; desarrollo territorial y urbano sostenible; control judicial.

\begin{abstract}
The advance of urban policies within the framework of the right to the city and the gradual inclusion of the principle of territorial and sustainable urban development means that aspects such as the gender perspective, sustainability, social cohesion or participation are increasingly present, in short, the search for more inclusive, more humane and more livable cities. In not too much time, it has gone from trying
\end{abstract}


to guarantee the fulfillment of certain aspects in the planning through the corresponding reports, formal procedure from the procedural point of view, to the inclusion of criteria in the new models of territorial and urban development with the incorporation of concrete measures aimed at their effectiveness. The work focuses, on the one hand, on analyzing when the gender impact report is required in the light of the recent jurisprudence of the Supreme Court and, on the other hand, on the novelty of the express recognition in jurisdictional headquarters of the right to the city and the principle of equal treatment, inspiring the new conception of sustainable urban and territorial development, as well as its gradual inclusion in the autonomous legislative frameworks.

\title{
KEYWORDS
}

Urbanism; principle of equal treatment; right to the city; sustainable territorial and urban development; judicial control.

\begin{abstract}
SUMARIO
INTRODUCCIÓN. 1. SOBRE EL INFORME DE EVALUACIÓN DE IMPACTO DE GÉNERO EN LOS PLANES URBANÍSTICOS Y LAS CONSECUENCIAS DE SU OMISIÓN A LA LUZ DE LA JURISPRUDENCIA. 1.1. CONTEXTO DE PARTIDA. 1.1.1. Sentencia del Tribunal Supremo de 6 de octubre de 2015: Nulidad del POTS de la Costa del Sol. 1.1.2. Sentencia del Tribunal Supremo de 27 de octubre de 2016: Informe de impacto de género en el Reglamento de la Ley de Costas. 1.2. SENTENCIA DEL TRIBUNAL SUPREMO DE 10 DE DICIEMBRE DE 2018: FIJACIÓN DE DOCTRINA JURISPRUDENCIAL SOBRE LA EXIGIBILIDAD DEL INFORME DE IMPACTO DE GÉNERO EN PLANES URBANÍSTICOS. 1.2.1. Antecedentes: la dificultad de Boadilla del Monte para dotarse de un PGOU y la Sentencia del Tribunal Superior de Justicia de la Comunidad de Madrid. 1.2.2. El recurso de casación ante el Tribunal Supremo y la doctrina fijada. 2. PRINCIPIO DE IGUALDAD DE TRATO COMO INSPIRADOR DE LA NUEVA CONCEPCIÓN DEL DESARROLLO URBANO. 2.1. PREVISIONES EN EL MARCO LEGISLATIVO ESTATAL. 2.2. INCLUSIÓN DEL PRINCIPIO DE IGUALDAD DE TRATO POR LAS LEGISLACIONES URBANÍSTICAS AUTONÓMICAS. 2.3. UN PASO MÁS: DE LOS PRINCIPIOS INSPIRADORES A LA INSTRUMENTALIZACIÓN DE LA IGUALDAD DE TRATO EN LAS LEGISLACIONES URBANÍSTICAS AUTONÓMICAS. 2.3.1. La memoria social de los planes urbanísticos. 2.3.2. Determinaciones específicas en el contenido sustantivo de los planes. 2.3.3. Criterios y reglas para la planificación con perspectiva de género: la apuesta valenciana. 2.3.4. Los criterios de sostenibilidad y su concreción en la perspectiva de género: el reto extremeño. REFLEXIONES FINALES. BIBLIOGRAFÍA.
\end{abstract}

\section{INTRODUCCIÓN}

Uno de los mayores problemas a los que se vienen enfrentando en los últimos años tanto los instrumentos de planificación territorial como de planeamiento urbanístico es su declaración de nulidad de pleno derecho por los Tribunales. En la mayoría de ocasiones, además, derivado de cuestiones formales y en consecuencia sin entrar a valorar la idoneidad del modelo previsto en aquéllos, el plano sustantivo de los instrumentos sometidos a revisión jurisdiccional.

Esta situación es de tal magnitud que ha llegado incluso a «rizar el rizo» con municipios que se han enfrentado hasta en dos ocasiones a la anulación de sus planes urbanísticos, con la consecuente inseguridad jurídica tanto para los ciudadanos para también para los propios municipios que se han visto durante décadas sin un instrumento que dotara de seguridad jurídica el marco de desarrollo del modelo de ciudad previsto sus planes $^{1}$. El motivo se sustenta en la consideración de los planes urbanísticos y territoriales como normas de carácter reglamentario a las que les resultan de aplicación las reglas de nulidad absoluta o nulidad de pleno derecho. Numerosos trabajos se han ocupado de analizar esta cuestión, desde hace años en el «candelero» de la polémica por los devastadores efectos que produce y por el elevado número de instrumentos que se han visto afectados por la aplicación de esta doctrina jurisprudencial que mantiene nuestro Alto Tribunal ${ }^{2}$. Aunque

\footnotetext{
1 A modo de ejemplo, la Sentencia del Tribunal Supremo de 17 de febrero de 2017 (ECLI: ES:TS:2017:623), venía a declarar nulo por segunda vez el Plan General de Ordenación Municipal del municipio gallego de Verín, aprobado en el año 2012.

2 Sobre el particular véase, entre otros, los trabajos de SANTAMARÍA PASTOR, J. A. (2016): "Una imprevista disfunción del sistema urbanístico: la mortalidad judicial de los planes", en Práctica Urbanística, núm. 141.; GONZÁLEZ SANFIEL, A. M. (2018): "Nulidad del planeamiento urbanístico e invalidez de los actos amparados en el mismo. Atención especial a las nuevas iniciativas legislativas al respecto",
} 
REALA. Nueva Época - N.o 12, octubre-marzo 2019 - ISSN: 1989-8975 - DOI: 10.24965/reala.i12.10702 - [Págs. 52-71]

Urbanismo y género: del informe de impacto de género al principio de igualdad de trato como inspirador de la nueva concepción...

Esther Rando Burgos

es difícil concretar el número de planes que se han visto afectados ${ }^{3}$, pese a los intentos de aproximarse a su cuantificación, las elevadas cifras y las graves consecuencias que se generan hace precisa una solución que se viene predicando como urgente. Sólo por omisión de la Evaluación Ambiental Estratégica, RAMOS cuantificaba en 2017, en más de noventa los planes urbanísticos anulados, el mismo autor, señalaba idéntica cifra al referirse a los planes de urbanismo anulados por no justificar la disponibilidad de recursos hídricos ${ }^{4}$.

La casuística, como decimos, es enorme. Ahora bien, en este contexto general, la reciente Sentencia del Tribunal Supremo, Sala de lo Contencioso, de 10 de diciembre de $2018^{5}$ (STS de 10 de diciembre de 2018), aborda diversas cuestiones de interés que van mucho más allá del mero pronunciamiento sobre la posible nulidad de un plan urbanístico por la omisión de un trámite formal. Por un lado, porque tras numerosas resoluciones en las que se anulaban instrumentos de planeamiento, no pocas motivadas por la carencia de alguno de los informes preceptivos exigidos por la legislación sectorial o urbanística, de manera casi sorpresiva, el Tribunal Supremo (TS) parece dar un cambio de rumbo (o al menos, deja ver un hilo de luz), revocando la nulidad de un Plan General de Ordenación Urbana (PGOU) que ya había sido anulado en la instancia, precisamente motivado en la carencia de uno de estos informes, en concreto el informe de impacto de género. Pero además, y precisamente por la particularidad de la materia, esta Sentencia lleva al TS a realizar por primera vez ciertas reflexiones sobre la importancia del principio de igualdad de trato en tanto inspirador de la nueva concepción del derecho a la ciudad.

Si bien el punto de partida se encuentra en la citada resolución judicial, no se trata de realizar un comentario a lo allí señalado, sino a partir de la doctrina que fija y tomándola como referente, por un lado, concretar cuándo será preciso dar cumplimiento a este trámite formal y por otro, tratar de ir un paso más allá, centrándonos en la segunda lectura de lo que allí se apunta: la inclusión del principio de igualdad de trato en la nueva concepción del desarrollo urbano y territorial.

El principio de desarrollo territorial y urbano sostenible, tiene un carácter transversal que obliga a dirigir un mandato a las diferentes políticas públicas con competencias sobre el suelo para el uso racional de los recursos naturales, armonizando los requerimientos de otras tantas funciones como la economía, el empleo, la salud o la protección del medio ambiente, pero también otras metas como la cohesión social, la seguridad de las personas o la igualdad de trato y de oportunidades. De ahí que el logro, o siquiera avance, hacia este modelo de desarrollo urbano sostenible obligue a conjugar de manera adecuada cada una de ellas y avanzar en las mismas de manera propia pero interrelacionada con la meta que se propugna.

Es muy necesario conocer los pronunciamientos contenidos en la meritada resolución judicial así como los antecedentes de mayor relevancia que han llevado a la misma. Para ello, el trabajo se centra en las dos cuestiones apuntadas, en el plano formal, el criterio doctrinal fijado en relación a la obligatoriedad de incluir el informe que valore el impacto de género en los planes urbanísticos y, en el sustantivo, el reconocimiento del principio de igualdad de trato como inspirador del nuevo modelo de desarrollo sostenible para, a partir del mismo, analizar cómo se viene imbricando paulatinamente en las legislaciones urbanísticas y cómo, de manera novedosa, algunas Comunidades Autónomas vienen optando por fijar criterios concretos dirigidos a, en efecto, lograr ciudades y territorios más inclusivos, más humanos, más habitables, o simplemente, si se quiere, ciudades «vivibles», para vivirlas y disfrutarlas.

en Documentación Administrativa. Nueva Época, núm. 5, págs. 46-68.; GONZÁLEZ SANFIEL, A. M. (2017): "Límites a la declaración de nulidad del planeamiento", en LÓPEZ RAMÓN, F. y VILLAR ROJAS, F. J. (coords.): El alcance de la invalidez de la actuación administrativa: Actas del XII Congreso de la Asociación Española de Profesores de Derecho Administrativo, págs. 411-459.; BASSOLS COMA, M. (2017): "La asimilación de los planes de urbanismo a normas reglamentarias y problemática jurídica de su anulación", en SORIA MARTíNEZ, G. y BASSOLS COMA, M. (coords.): Los efectos de la nulidad de los instrumentos de planeamiento urbanístico, págs. 27-102.; BAÑO LEÓN, J. M. (2016): "Reconsideración sobre el régimen de impugnación del plan urbanístico", en GIFREU i FONT, J., BASSOLS COMA, M. y MENÉNDEZ REXACH, A. (dirs.): El derecho de la ciudad y el territorio: estudios en homenaje a Manuel Ballbé Prunés, págs. 859-871.; BAÑO LEÓN, J. M. (2017): "El plan urbanístico en ruina: un esbozo de reconstrucción", en Práctica Urbanística, núm. 144.; BAÑO LEÓN, J. M. (2017): "Un plan jurídico de reforma para los planes urbanísticos", en Revista de Derecho Urbanístico y Medio Ambiente, núm. 311, págs. 43-56.; GUTIÉRREZ COLOMINA, V. (2016): "Los efectos de la nulidad de los planes urbanísticos en Andalucía y su repercusión en las edificaciones ilegales", en Revista Andaluza de Administración Pública, núm. 96, págs. 47-84.; RENAU FAUBELL, F. (2016): "La nulidad «radioactiva» de los planes urbanísticos por defectos en el procedimiento de aprobación". Noticias Jurídicas, artículos doctrinales.

${ }^{3}$ Sobre esta cuestión, GONZÁLEZ SANFIEL señala que, aunque a través de la jurisprudencia se han ido conociendo la gran cantidad de planes y actos administrativos de contenido urbanístico que han sido anulados en nuestro país, «no existen estadísticas, ni cifras ciertas». En GONZÁLEZ SANFIEL, A. M. (2018): "Nulidad del planeamiento urbanístico e invalidez de los actos..." cit.

${ }^{4}$ RAMOS MEDRANO, J. A. (2017): "Más de 90 planes de urbanismo anulados judicialmente por no realizar la Evaluación Ambiental Estratégica (EAE)", en Actualidad Jurídica Ambiental, núm. 73 y RAMOS MEDRANO, J. A. (2017): "Más de 90 planes de urbanismo anulados judicialmente por no justificar la disponibilidad de los recursos hídricos”, en Actualidad Jurídica Ambiental, núm. 67.

5 ECLI:ES:TS:2018:4087. 


\section{SOBRE EL INFORME DE EVALUACIÓN DE IMPACTO DE GÉNERO EN LOS PLANES URBANÍSTICOS Y LAS CONSECUENCIAS DE SU OMISIÓN A LA LUZ DE LA JURISPRUDENCIA}

\subsection{Contexto de partida}

Hasta la reciente STS de 10 de diciembre de 2018, se había tenido ocasión de conocer el criterio mantenido por el Alto Tribunal ante la inexistencia del conocido como «informe de impacto por razón de género», principalmente, en dos resoluciones judiciales, la STS de 6 de octubre de 2015 que anuló el Plan de Ordenación del Territorio de la Costa del Sol (POTS de la Costa del Sol) y la STS de 27 de octubre de 2016 que resolvía el recurso planteado frente al Reglamento de la Ley de Costas.

\subsubsection{Sentencia del Tribunal Supremo de 6 de octubre de 2015: Nulidad del POTS de la Costa del Sol}

Ya en 2015, este motivo fue uno de los dos que determinó la nulidad del POTS de la Costa del Sol. Así, la STS, Sala de lo Contencioso, de 6 de octubre de $2015^{6}$, venía, tras casi una década de vigencia, a anular el Decreto del Consejo de Gobierno de la Junta de Andalucía 142/2006, de 18 de julio, por el que fue aprobado ${ }^{7}$.

La Sentencia se centra en determinar si, como alega la demandada, la falta del informe de evaluación de impacto de género era o no preceptivo como trámite exigible en la elaboración y aprobación del plan. La razón de su decisión se encuentra en la previsión del art. 139.1 de la Ley andaluza 18/2003, de 29 de diciembre, por la que se aprueban medidas fiscales y administrativas, que establecía que todos los proyectos de ley y reglamentos aprobados por el Consejo de Gobierno debían tener en cuenta de forma efectiva el objetivo de la igualdad por razón de género y, a tal fin, en la tramitación de las citadas disposiciones debía emitirse un informe de evaluación de impacto por razón de género del contenido de las mismas. Posteriormente desarrollado por el Decreto 93/2004, de 9 de marzo, por el que se regula el informe de evaluación de impacto de género en los proyectos de ley y reglamentos aprobados por el Consejo de Gobierno, cuyo art. 2 determina que el cumplimiento de sus previsiones afecta a todos los proyectos de ley y reglamentos aprobados por el Consejo de Gobierno, a la vez que en los arts. 3 y 4, regula el órgano competente para emitirlo y su contenido, respectivamente. Al entender de la Sala, la aprobación del POTS de la Costa del Sol mediante Decreto 142/2006, de 18 de julio, tuvo lugar cuando tanto la Ley 18/2003 como el Decreto 93/2004, estaban vigentes, entendiendo que el informe era preceptivo. De esta forma, sustenta su posición en la Ley estatal 30/2003, de 13 de octubre, que modificó el art. 24 de la Ley 50/1997, de 27 de noviembre, del Gobierno, para introducir en su aptdo.1.b) la exigencia de un informe de impacto por razón de género en el procedimiento de elaboración de reglamentos, de aplicación supletoria, en virtud de la previsión de la disposición transitoria, aptdo. 2, de la Ley 6/1983, de 21 de julio, del Gobierno y Administración de la Comunidad Autónoma de Andalucía ${ }^{8}$.

Estos motivos son, en síntesis, los que llevan a la Sala a concluir que en el procedimiento de elaboración del POTS Costa del Sol debió emitirse un informe de evaluación de impacto por razón de género. Pese a que insiste en otras normas posteriores a la entrada en vigor del plan, como la Ley 12/2007, de 2 de noviembre, para la Promoción de la Igualdad de Género en Andalucía (precisamente, cuyo art. 6 prevé la obligatoriedad de que se incorpore de forma efectiva el objetivo de la igualdad por razón de género en todos los proyectos de ley, reglamentos y planes que apruebe el Consejo de Gobierno, a través de un informe de evaluación del impacto de género del contenido de las mismas), la reforma del Estatuto de Autonomía de Andalucía aprobado por Ley Orgánica 2/2007, de 19 de marzo, o el propio Decreto autonómico 17/2012, de

\footnotetext{
6 ECLI:ES:TS:2015:4382.

7 Esta cuestión fue abordada en nuestro trabajo (2016) "La relevancia del procedimiento de tramitación de los instrumentos de planificación territorial: la nulidad del Plan de Ordenación del Territorio de la Costa del Sol de Málaga por la Sentencia del Tribunal Supremo de 6 de noviembre de 2015". Ponencia VII Congreso Internacional de Ordenación del Territorio: nuevos tiempos, nuevos objetivos. Fuerteventura 25, 26 y 27 de mayo de 2016, págs. 925-936. También sobre nulidad de planes territoriales, nos hemos referido en (2018) "La anulación del Plan de Protección del Corredor Litoral de Andalucía por el Tribunal Superior de Justicia de Andalucia: ¿nuevas dificultades en la planificación territorial de Andalucía?”. Revista de Estudios de la Administración Local y Autonómica: Nueva Época, núm. 10, págs. 109-131.

8 Precepto que disponía «Igualmente, es de aplicación la legislación del Estado, supletoria o analógicamente, para el régimen jurídico procesal, previsto para el mismo en la legislación vigente, y al correspondiente al de los contratos, los bienes, la responsabilidad patrimonial, los funcionarios y demás aspectos no regulados en esta ley, hasta tanto no se produzca la legislación correspondiente de la Comunidad Autónoma de Andalucia».
} 
7 de febrero, que regula la elaboración del informe de impacto de género, ninguna relevancia tienen al objeto enjuiciado ya que, como reconoce la propia Sentencia, no se encontraban vigentes al momento de entrada en vigor del plan territorial.

Obvia, sin embargo, el momento en que formalmente se acuerda la elaboración y tramitación del plan, con el Decreto 8/2004, de 20 de enero ${ }^{9}$, momento en que no estaba vigente aún el Decreto 93/2004 ${ }^{10}$. No así, el magistral voto particular de la Sentencia formulado por el Magistrado Excmo. Sr. D. José Juan Suay Rincón, al que se adhiere el Magistrado Excmo. Sr. D. Marino de Oro Pulido y López, que, con un pormenorizado análisis disiente de tal entender, indicando que «...no comparto que el informe de evaluación de impacto de género resultara exigible y constituya un imperativo insoslayable, de tal manera que su omisión desembocara en las consecuencias que la sentencia extrae de ella.... Al menos, al tiempo en que vino a tramitarse y aprobarse el instrumento de ordenación territorial sometido a nuestro enjuiciamiento...».

En primer lugar, parece obviarse el carácter bifásico de tramitación de los planes urbanísticos o territoriales. En concreto, el que ocupa, efectivamente, se formula antes de la aprobación y entrada en vigor del Decreto 93/2004. Es a partir de este momento cuando comienza formalmente la elaboración del instrumento que se completará en una fase posterior cuando, redactado y cumplimentado los preceptivos trámites, será finalmente aprobado.

El voto particular contiene otros pronunciamientos relevantes referidos a aspectos como la transversalidad del informe de impacto por razón de género y su alcance horizontal; el eje en torno al que realmente gira la controversia: el carácter reglamentario de los planes; o, el encaje del debate en la normativa autonómica vigente.

En relación al principio de transversalidad, como fundamento de la exigibilidad del informe de impacto por razón de género, se reconoce su proyección general y su propio germen en el Tratado de Amsterdam pero, pese a su relevancia, atendiendo a la normativa andaluza vigente en el momento de aprobación del plan, el voto particular precisa que «...el informe de impacto por razón de género no se proyecta sobre la totalidad de los instrumentos puestos a disposición de la Comunidad Autónoma para el desarrollo de su acción de gobierno, sino que dicho informe contrae su ámbito de aplicación, señaladamente, a los proyectos de leyes y reglamentos cuya aprobación corresponde al Consejo de Gobierno de la Junta de Andalucía ».

Se confirma el alcance horizontal del principio de transversalidad que se extiende a los distintos sectores de la actividad administrativa precisamente por su carácter transversal, si bien, conforme al tenor literal de la normativa señalada, limitado a los proyectos de leyes y reglamentos. Y aquí se encuentra el eje principal de la cuestión a dilucidar, en determinar si el POTS Costa del Sol constituye o no un reglamento, lo que determinará su exigencia. Con un detallado análisis, el voto particular se centra en clarificarlo. Parte del carácter de disposición general que se predica tanto de los planes territoriales como urbanísticos, recordando la jurisprudencia que en su día precisó que «...los planes urbanísticos tenían una naturaleza jurídica asimilada a la de las disposiciones de carácter general» y aun sin cuestionar su esencia normativa, sí pone sobre la mesa la peculiaridad de los mismos, en cuanto disponen de una regulación específica y completa en el ordenamiento jurídico en que se integran que incluso se reconoce en la propia normativa general (con remisión a la Ley 7/1985, de 2 de abril, Reguladora de las Bases del Régimen Local, que distingue entre potestad reglamentaria y de autoorganizacion y potestad de programación o planificación).

Reconociendo «la inexistencia de una identidad completa en la sujeción de los reglamentos a las mismas normas procedimentales», por lo que «en todo caso, que se convenga en la consideración de los planes urbanísticos y territoriales como disposiciones de carácter general no quiere decir que les resulten de aplicación sin más las mismas previsiones normativas sin excepción de ningún género». Abundando en esta idea recuerda, cómo ni siquiera la potestad reglamentaria en sentido estricto está sujeta exactamente a las mismas reglas. $Y$ es tajante al afirmar que, aun en el caso de reconducir los planes a alguna de las dos categorías básicas y primarias de normas y actos, se encuadran en las primeras, sin que ello sea óbice para que los planes tengan que atender a «...una recepción absoluta de las normas reguladoras de los reglamentos estatales y autonómicos...», para concluir que «...para la exigibilidad del informe de impacto por razones de género, dicho informe ha de venir exigido por la correspondiente normativa urbanística».

Para terminar, el voto particular se ocupa de analizar «el posible surgimiento de la controversia, en cualquier caso, a partir de una normativa autonómica posterior», reconociendo que, a lo sumo, la controversia podría plantearse a partir de la normativa vigente (posterior a la aprobación del plan), en la medida en

\footnotetext{
BOJA núm. 29, de 12-02-2004.

10 BOJA núm. 50, de 12-03-2004.
} 
REALA. Nueva Época - N.o 12, octubre-marzo 2019 - ISSN: 1989-8975 - DOI: 10.24965/reala.i12.10702 - [Págs. 52-71]

Urbanismo y género: del informe de impacto de género al principio de igualdad de trato como inspirador de la nueva concepción..

Esther Rando Burgos

que la Ley 12/2007, de 26 de noviembre, dictada en cumplimiento del mandato contenido en el Estatuto de Autonomía de Andalucía de $2007^{11}$, sí se refiere expresamente, al exigir el informe de impacto por razón de género, no sólo a los reglamentos, sino también a los planes aprobados por el Consejo de Gobierno de la Junta de Andalucía. Coincidimos plenamente que dicha matización del legislador al optar por incluir junto a los reglamentos y proyectos de ley, expresamente los «planes aprobados por el Consejo de Gobierno», es esencial y clarifica de manera indubitada la distinción que abunda en la idea de que, en efecto, al momento de aprobación del plan territorial no estaba expresamente prevista la obligación para los mismos.

\subsubsection{Sentencia del Tribunal Supremo de 27 de octubre de 2016: Informe de impacto de género en el Reglamento de la Ley de Costas}

Entre las resoluciones sobre el preceptivo informe sobre el impacto por razón de género, es también referente la STS de 27 de octubre de $2016^{12}$. El pronunciamiento se centra en diferentes reproches jurídicos contra el Reglamento General de la Ley de Costas, aprobado por Real Decreto 876/2014, de 10 de octubre. Entre otros, por la demandada, se alega la inexistencia de un informe sobre el impacto por razón de género de las medidas que se establecen en el Reglamento, infringiéndose la previsión del art. 24.1.b) de la ya citada Ley 50/1997, así como el art. 2.1.d) del Real Decreto 1083/2009, de 3 de julio, por el que se regula la Memoria de Análisis de Impacto Normativo (MAIN) y el art. 19 de la Ley Orgánica 3/2007, de 22 de marzo, para la Igualdad Efectiva de Mujeres y Hombres ${ }^{13}$.

Pues bien, en este caso, el Alto Tribunal, desestima el motivo, sustentado en que «El impacto de género se considera cuando no existiendo desigualdades de partida en relación a la igualdad de oportunidades y de trato entre mujeres y hombres, no se prevea modificación alguna de esta situación». Reprocha la Sentencia que si bien como reconoce la recurrente "...la MAIN elaborada...señala que "[e]l impacto en función del género del proyecto es nulo...", si bien con ello se infringe de forma grosera la Guía Metodológica redactada por el Ministerio de Presidencia, al confundir la conclusión del análisis con el análisis de impacto de género...», por parte de ésta no se «ha puesto de manifiesto la existencia de argumento alguno para desmontar el juicio contenido en la MAIN del RGC en el sentido de que la incidencia del mismo en las políticas de género no sea "nulo"». Y continúa su motivación indicando que «...la recurrente no acierta a determinar cuáles serían las incidencias del nuevo RGC en el régimen de la igualdad entre hombres y mujeres, por cuanto, como hemos expresado, la incidencia del RGC sobre la población o las zonas litorales resultan genéricas y poco cercanas a la afectación de las políticas de género...».

A la luz de esta Sentencia se parece moderar el criterio sostenido, exigiéndose la concreción de la incidencia del Reglamento sobre la igualdad entre hombres y mujeres, incluso afirmándose la escasa o, en palabras de la STS, "genérica» incidencia sobre la población o las zonas litorales de esta norma legal cuyo objeto es precisamente desarrollar las previsiones de la Ley de Costas. Tanto es así que desestima el motivo y reprocha a la recurrente la carencia de argumentos que lleven a conocer la incidencia de la norma en las políticas de género, distanciándose con ello del criterio sostenido en la STS de 6 de octubre de 2015 que anula el POTS Costa del Sol en el que la recurrente tampoco parece precisar la incidencia que las determinaciones del plan puedan tener para la igualdad propugnada entre hombres y mujeres, según alega la Administración demandada que también señala la no emisión del informe por la inexistencia en el plan de determinaciones con incidencia en materia de género (FD Cuarto).

\subsection{Sentencia del Tribunal Supremo de 10 de diciembre de 2018: fijación de doctrina jurisprudencial sobre la exigibilidad del informe de impacto de género en planes urbanísticos}

La reciente STS de 10 de diciembre de 2018, como se indicaba, aborda diversas cuestiones de interés. En primer lugar, y desde el plano formal, el criterio doctrinal fijado relativo a la obligatoriedad de incluir el informe que valore el impacto de género en los planes urbanísticos, cuestión sobre la que el Tribunal Supremo fija:

11 En concreto, su art. 114 establece que «En el procedimiento de elaboración de las leyes y disposiciones reglamentarias de la Comunidad Autónoma se tendrá en cuenta el impacto por razón de género del contenido de las mismas».

12 ECLI:ES:TS:2016:4762.

13 Precepto que dispone «Los proyectos de disposiciones de carácter general y los planes de especial relevancia económica, social, cultural y artística que se sometan a la aprobación del Consejo de Ministros deberán incorporar un informe sobre su impacto por razón de género». 
...la cláusula de aplicación supletoria del derecho estatal no permite sostener la exigencia a las Comunidades Autónomas de un requisito, como es el informe de impacto de género, en materia de ordenación urbanística, que no figura previsto en su propia legislación.

Parece con ello resolverse la controversia que venía produciéndose en torno a si por la aplicación supletoria de la previsión contenida a nivel estatal en el art. 24.1.b.) de la Ley 50/1997, en su redacción dada por la Ley 30/2003, de 13 de octubre, sobre medidas para incorporar la valoración del impacto de género en las disposiciones normativas que elabore el Gobierno, resultaba exigible el informe de impacto por razón de género en el procedimiento de elaboración de reglamentos y, por extensión de aquéllos, de planes urbanísticos o territoriales.

\subsubsection{Antecedentes: la dificultad de Boadilla del Monte para dotarse de un PGOU y la Sentencia del Tribunal Superior de Justicia de la Comunidad de Madrid}

Se apuntaba con anterioridad, el auténtico periplo (o «labor titánica» como lo denomina el TSJ de la Comunidad Valenciana en Sentencia de 5 de diciembre de 2011 ${ }^{14}$ ) que supone la tramitación y aprobación de un instrumento de planeamiento urbanístico general. A lo que se suma, con la doctrina actual, un segundo «filtro»: superar con éxito la revisión por los órganos jurisdiccionales del referido instrumento ${ }^{15}$.

Boadilla del Monte es un claro ejemplo de ello. Es uno de los municipios que se ha enfrentado hasta en dos ocasiones a la anulación de su Plan General de Ordenación Urbana (PGOU). En 2001, el municipio aprobaba el PGOU, declarado nulo por el Tribunal Supremo en Sentencia de 12 de noviembre de $2010^{16}$. El motivo traía causa en la STS de 5 de febrero de 2003, recaída en el procedimiento especial de protección de derechos fundamentales frente al Acuerdo de aprobación provisional del plan «....al haberse producido una vulneración del artículo 23 de la Constitución por cuanto se sustrajo a determinados concejales el acceso a una documentación que era relevante, lo que les impidió el normal ejercicio de su labor de control y fiscalización de la actividad municipal...».

Tras la tramitación de un nuevo instrumento, sería mediante Acuerdo de 20 de octubre de 2015, del Consejo de Gobierno de la Comunidad de Madrid, cuando se aprobaría el PGOU de Boadilla del Monte. Recurrido en la instancia, la demandada alega tres motivos impugnatorios, entre ellos, la omisión en el procedimiento de aprobación del PGOU de un informe sobre impacto de género. Desestimados los restantes, es éste último el acoge la Sala que falla, con estimación del recurso, declarando su nulidad.

La STSJ de Madrid, de 19 de abril de $2017^{17}$, realiza un pormenorizado análisis que parte de un recorrido doctrinal y de diferentes instrumentos y acuerdos internacionales, para más tarde reproducir «para mayor claridad de nuestros propios fundamentos jurídicos», buena parte de los razonamientos contenidos en la STS de 6 de octubre de 2015, realizando casi un análisis de contraste entre los hechos enjuiciados en ambas.

Parte para ello del análisis del Estatuto de Autonomía de Madrid y la previsión en el mismo, en materia de igualdad, de un mandato contenido en el art 7.4 que, en consonancia con el art. 9.2 de la Constitución Española (CE), atribuye a los poderes autonómicos, en el ámbito de su competencia, promover las condiciones para que la libertad y la igualdad del individuo y de los grupos en que se integran sean reales y efectivas, así como la atribución a la Comunidad Autónoma de la competencia exclusiva en materia de promoción de la igualdad respecto a la mujer que garantice su participación libre y eficaz en el desarrollo político, social, económico y cultural. Así como su desarrollo en dos leyes autonómicas (Ley 2/2016, de 29 de marzo, de Identidad y Expresión de Género e Igualdad Social y No Discriminación y Ley 3/2016, de 22 de julio, de Protección Integral contra la LGTBifobia y la Discriminación por Razón de Orientación e Identidad Sexual), optando por entender que al no ser éstas últimas aplicables en aquel momento, su ausencia justifica la aplicación supletoria del entonces vigente art. 24 de la Ley 50/1997, abundando en la previsión contenida en el art. 33 del Estatuto de Autonomía que «...prevé el carácter, en todo caso, supletorio del Derecho del Estado respecto del propio de la Comunidad de Madrid».

14 Vid. RENAU FAUBELL, F. (2016): “La nulidad «radioactiva» de los planes urbanísticos...", cit.

15 Sobre las «perversas consecuencias de los conflictos jurídicos y la creciente litigiosidad» de los planes, nos hemos referido con mayor detenimiento en nuestro trabajo, Régimen Jurídico de la Gestión Territorial. Tirant Lo Blanch, en prensa.

16 ECLI:ES:TS:2010:6338.

17 ECLI:ES:TSJM:2017:3416. 
REALA. Nueva Época - N.o 12, octubre-marzo 2019 - ISSN: 1989-8975 - DOI: 10.24965/reala.i12.10702 - [Págs. 52-71]

Urbanismo y género: del informe de impacto de género al principio de igualdad de trato como inspirador de la nueva concepción..

Esther Rando Burgos

Esta Sentencia, como era de esperar, no pasó desapercibida. Como plantea Fuertes, trayendo a colación un debate de actualidad en torno a las nefastas consecuencias de la omisión de trámites formales en la tramitación de los planes urbanísticos, «... ¿No parece desproporcionado que la inexistencia de tal informe eche por tierra años de trabajo? Luchar por la igualdad, lo mismo que atender a las personas más vulnerables y dependientes, o preocuparse y cuidar del entorno son presupuestos que debe atender todo Ayuntamiento. Pero me parece algo exagerado que sin acreditar qué menoscabos concretos para las mujeres, qué perjuicios reales existen para el desenvolvimiento de sus actividades se declare la nulidad de todo un Plan general de ordenación urbana.... ${ }^{18}$. En efecto, coincidimos en que el logro de unas ciudades integradoras, inclusivas o habitables, tanto desde el punto de vista de la igualdad de género como desde la perspectiva de la búsqueda de la igualdad para personas vulnerables o dependientes, no puede reducirse a un simple trámite administrativo consistente en la cumplimentación de un informe, es una cuestión de mayor calado que precisa dotarse de los mecanismos adecuados que hagan efectiva y real la meta planteada.

\subsubsection{El recurso de casación ante el Tribunal Supremo y la doctrina fijada}

Tanto la Comunidad de Madrid como el Ayuntamiento de Boadilla del Monte, presentaron sendos recursos de casación frente a la meritada resolución judicial, reprochando la indebida aplicación supletoria del art. 24 de la Ley 50/1997 y del art. 19 de la Ley Orgánica 3/2007, en relación con el art. 33 del Estatuto de Autonomía, en tanto parte del bloque de constitucionalidad en conexión con el art. 149.3 de la CE.

Admitido el recurso por presentar interés casacional objetivo para la formación de la jurisprudencia, constriñendo a la determinación por el TS de «en qué medida la cláusula de aplicación supletoria del derecho estatal permite sostener la exigencia a las Comunidades Autónomas de un requisito, como es el informe de impacto de género, en materia de ordenación urbanística, que no figura previsto en su propia legislación».

La Sentencia, en su FD Séptimo, es tajante al aclarar que su función no es pronunciarse sobre la conveniencia u oportunidad de que los instrumentos de planeamiento urbanístico incorporen o no un informe de perspectiva de género, sino centrarse en el caso concreto y determinar si para el PGOU sometido a debate era requisito incorporarlo, así como si su ausencia podría dar lugar a la nulidad del mismo.

$Y$ en este punto centra su pronunciamiento, en la supletoriedad del derecho estatal, recordando que dicha cláusula es una previsión constitucional emanada de la Constitución y dirigida al aplicador del Derecho, indicándole el modo en que deben colmarse las lagunas del ordenamiento jurídico cuando las haya. Ahora bien, la cláusula de supletoriedad no permite que el derecho estatal colme, sin más, la falta de regulación autonómica en una materia.

No si antes recoger alguno de los análisis de las Sentencias en que ya tuvo ocasión de pronunciarse y del propio voto particular suscrito frente a la STS de 10 de octubre de 2015, se centra en dilucidar la cuestión sometida a su debate. Y parte de la tesis central de la Sentencia recurrida que mantiene que debía observarse el art. 24 de la Ley 50/1997, modificado por la Ley 30/2003, ya que, en ausencia de normativa específica autonómica, el art 33 del Estatuto de Autonomía establece el carácter, en todo caso, supletorio del derecho estatal respecto del propio derecho autonómico para, a continuación, relacionar diferentes STC que se pronuncian sobre la supletoriedad del derecho estatal, trayendo a colación, entre otras, la STC 118/96 y recordando que «La cláusula de supletoriedad es... una previsión constitucional emanada de la Constitución que se dirige al aplicador del Derecho, indicándole el modo en que deben colmarse las lagunas del ordenamiento autonómico, cuando las haya... Una vez que el aplicador del Derecho, utilizando los medios usuales de interpretación haya identificado una laguna en el ordenamiento autonómico, deberá colmarla acudiendo a las normas, pertinentes, dictadas por el Estado en el ejercicio de las competencias que la Constitución le atribuye; en eso consiste la supletoriedad del Derecho estatal que, por su misma naturaleza, no comporta atribución competencial alguna... la cláusula de supletoriedad no permite que el Derecho estatal colme, sin más, la falta de regulación autonómica en una materia. El presupuesto de aplicación de la supletoriedad que la Constitución establece no es la ausencia de regulación, sino la presencia de una laguna detectada como tal por el aplicador del Derecho... de lo contrario, la ley estatal sería aplicable en el ámbito reservado al Derecho autonómico sobre la ase de la mera ausencia de regulación autonómica...».

18 FUERTES LÓPEZ, M. (2017): "Sentencias que anulan planes urbanísticos”. El blog de esPublico (https://www.administracionpublica.com/sentencias-que-anulan-planes-urbanisticos/\#). 
Como colofón, el TS reconoce que, en efecto, la previsión del art. 24 de la Ley 50/1997, constriñe su ámbito de aplicación a la potestad reglamentaria del Gobierno, no pudiéndose reputar procedimiento administrativo común a los efectos del art. 149.1.18 CE y tampoco puede constituir derecho supletorio conforme al art. 149.3 CE, para concluir que «...la cláusula de supletoriedad que se invoca para aplicar el artículo 24 de la Ley del Gobierno en relación con la elaboración del Plan de Ordenación, y por lo tanto exigir el informe de impacto de género como elemento esencial para la aprobación de dicho instrumento urbanístico, no tiene soporte en la actual jurisprudencia que analiza el señalado principio», estimando las pretensiones de las recurrentes en casación y fijando como doctrina que «...la cláusula de aplicación supletoria del derecho estatal no permite sostener la exigencia a las Comunidades Autónomas de un requisitos, como es el informe de impacto de género, en materia de ordenación urbanística, que no figura en su propia legislación...».

En síntesis, la Sentencia no hace sino reconocer el principio de competencia en la articulación de las relaciones entre el ordenamiento estatal y los autonómicos que supone la aplicación de la norma por quien ostente la competencia, limitando la predicada supletoriedad del art. 149.3, in fine, de la CE. Como afirma el profesor Rebollo, en referencia al principio de competencia y las matizaciones derivadas de la posible supletoriedad del derecho estatal, «El principio de competencia supone que sólo será aplicable la norma, estatal o autonómica, aprobada por quien tenga la competencia para ello, sea el Estado o sea una Comunidad Autónoma», clarificando el diferente alcance y sus consecuencias, según sea la norma autonómica o la estatal, la que regule las competencias asignadas a la otra Administración territorial, lo que para el caso de normas estatales que regulen aspectos competencia de una Comunidad Autónoma, el autor distingue dos consecuencias jurídicas: su nulidad en unos casos y su validez pero como norma supletoria de la regulación de la Comunidad Autónoma, en otros ${ }^{19}$.

\section{PRINCIPIO DE IGUALDAD DE TRATO COMO INSPIRADOR DE LA NUEVA CONCEPCIÓN DEL DESARROLLO URBANO}

Se señalaba con anterioridad que la relevancia de la STS de 10 de diciembre de 2018, viene dada, en buena medida, en que por primera vez nuestro Alto Tribunal, acogiendo las formulaciones de la Sentencia del TSJ de Madrid que revoca, se refiere propiamente al derecho a la ciudad y al principio de igualdad de trato como inspirador de la nueva concepción del desarrollo urbano.

Cada vez más imperante, el derecho a la ciudad no es, ni por asomo, algo desconocido. Propiamente, se remonta al año 1968 cuando Henri Lefebvre acuñó el término que diera nombre a su libro "El derecho a la ciudad" 20 con el que ponía sobre la mesa la reivindicación del derecho de los habitantes urbanos a construir, decidir y crear la ciudad, haciendo de ésta un espacio privilegiado. Décadas después, nuevamente se encuentra en el centro del debate, lo que para autores como Molano se debe a «...la explosión de nuevas luchas urbanas contra las expresiones espaciales del dominio del capital financiero, como la gentrificación o la degradación ambiental, pero también, al esfuerzo de los habitantes por lograr una mayor injerencia en la definición de las políticas urbanas» ${ }^{21}$.

Años más tarde, en 2004, la Carta Mundial por el Derecho a la Ciudad ${ }^{22}$, amplía el entendimiento del derecho a la ciudad, dotándolo de un articulado en el que se precisa el concepto y se fija su contenido; se establecen los principios y fundamentos estratégicos del derecho a la ciudad; se enumeran los derechos relativos al ejercicio de la ciudadanía y a la participación en la planificación, producción y gestión de la ciudad; así como los derechos de la ciudadanía en relación al desarrollo económico, social, cultural y ambiental de la ciudad. El derecho a la ciudad lo conceptúa como aquel por el que «Todas las personas tienen derecho a la ciudad sin discriminaciones de género, edad, condiciones de salud, ingresos, nacionalidad, etnia, condición migratoria, orientación política, religiosa o sexual, así como a preservar la memoria y la identidad cultural en conformidad con los principios y normas que se establecen en esta Carta», pero va más allá, reconociéndolo como derecho colectivo de los habitantes de las ciudades «en especial de los grupos vulnerables y desfavorecidos».

19 REBOLLO PUIG, M. (2017): "Relaciones entre el ordenamiento estatal y los autonómicos", en REBOLLO PUIG, M. y VERA JURADO, D. J. (dirs.): Derecho Administrativo, vol. I: Conceptos Fundamentales, Fuentes y Organización. Madrid: Tecnos.

20 LEFEBVRE, H. y GAVIRIA, M. (1969): El derecho a la ciudad. Barcelona: Península.

21 MOLANO CAMARGO, F. (2016): "El derecho a la ciudad: de Henri Lefebvre a los análisis sobre la ciudad capitalista contemporánea", en Folios: Revista de la Facultad de Humanidades, núm. 44, págs. 3-19.

22 HABITAT INTERNATIONAL COALITION (2012): "Carta Mundial por el Derecho a la Ciudad", en Revista de Paz y Conflictos, núm. 5, págs. 184-196. 
REALA. Nueva Época - N.o 12, octubre-marzo 2019 - ISSN: 1989-8975 - DOI: 10.24965/reala.i12.10702 - [Págs. 52-71]

Urbanismo y género: del informe de impacto de género al principio de igualdad de trato como inspirador de la nueva concepción..

Esther Rando Burgos

También otros documentos se han encargado de ir perfilando y dotando de contenido este derecho, es el caso de la Carta-Agenda Mundial de Derechos Humanos en la Ciudad de 2011, adoptada por el Consejo Mundial de CGLU (Ciudades y Gobiernos Locales Unidos) y auspiciada por la Comisión de Inclusión Social, Democracia Participativa y Derechos Humanos de CGLU, cuyo objetivo viene dado por «...la promoción y consolidación de los derechos humanos de todas las personas que habitan todas las ciudades del mundo». En realidad, se está ante algo de mayor entidad, nos encontramos ante una manifestación del proclamado desarrollo urbano sostenible. En este sentido, Lora-Tamayo apunta como ya en el año 1997, en el marco del documento aprobado por la Comisión "Hacia una política urbana de la Unión Europea", se establecen una serie de objetivos encaminados a coordinar y orientar las políticas comunitarias a los problemas urbanos, permitiendo de esta forma una intervención puntual y la financiación de programas, campañas y proyectos de enfoque más claro, y es aquí, como destaca la autora, donde se fijan como objetivos del desarrollo urbano sostenible, entre otros, «el fomento de la igualdad, la integración social y la regeneración en zonas urbanas especialmente en aquellas áreas y colectivos que sufren discriminación, exclusión social, marginación y de convivencia» ${ }^{23}$.

Más reciente en el tiempo, la Agenda Urbana 2030 para el Desarrollo Sostenible ${ }^{24}$, en la que se definen 17 objetivos de aplicación universal para todos los países dirigidos al logro de un mundo sostenible con la meta del año 2030. Entre los Objetivos de Desarrollo Sostenible (ODS), el ODS 5 está dedicado a «Lograr la igualdad de género y empoderar a todas las mujeres y las niñas» ${ }^{25}$.

En síntesis, éstos y otros documentos, pese a su carácter jurídicamente no vinculante, cada vez insisten con más fuerza en la necesidad y objetivo común de materializar el principio de igualdad del conjunto de la ciudadanía que habita en las diferentes ciudades a usarla, desenvolverse y disfrutar de la misma en condiciones de igualdad. Este derecho lleva a que de manera particular se deba atender a aquellos ciudadanos que por diversas circunstancias (edad, salud, vulnerabilidad u otras), mayores dificultades presentan para desenvolverse en la misma en condiciones de igualdad. Éste parece ser el sentido de «grupos vulnerables» a los que se refiere explícitamente la Carta Mundial por el Derecho a la Ciudad.

\subsection{Previsiones en el marco legislativo estatal}

La Ley Orgánica $3 / 2007$, lidera el grupo normativo dedicado a regular la igualdad efectiva de mujeres y hombres, desarrollando los arts. 14 y 9.2 de la CE e inspirado por un nutrido grupo de normas internacionales $^{26}$, completado por un cada vez más amplio conjunto de normas autonómicas ${ }^{27}$. De manera muy reciente,

${ }^{23}$ LORA-TAMAYO VALLVÉ, M. (2006): Derecho urbanístico y medio ambiente: hacia el desarrollo urbano sostenible. Madrid: Dykinson.

${ }^{24}$ ASAMBLEA GENERAL DE NACIONES UNIDAS (2015): Transformar nuestro mundo: la Agenda 2030 para el Desarrollo Sostenible.

${ }^{25}$ Vid. PÉREZ DEL PRADO, D. (2018): "Una aproximación a los indicadores de cumplimiento de los ODS desde la perspectiva de género", en Revista de Información Laboral, núm. 17, págs. 175-194.

${ }^{26} \mathrm{La}$ igualdad entre mujeres y hombres es un principio jurídico universal reconocido en diferentes textos internacionales sobre derechos humanos, como la Convención sobre la eliminación de todas las formas de discriminación contra la mujer (Asamblea General de Naciones Unidas de diciembre de 1979, ratificada por España en 1983), pero también por otras Conferencias internacionales auspiciadas por las Naciones Unidas sobre la mujer, como Ciudad de México (1975), Copenhague (1980), Nairobi (1985) o Beijing (1995). La igualdad también se instituye en principio fundamental de la Unión Europea, con la entrada en vigor del Tratado de Ámsterdam, el 1 de mayo de 1999, la igualdad entre mujeres y hombres y la eliminación de desigualdades se alza en objetivo que ha de integrarse en todas las políticas y acciones de la Unión y de los Estados miembros.

${ }^{27}$ Entre la normativa autonómica sobre igualdad puede citarse, sin ánimo de exhaustividad: Ley 12/2007, de 26 de noviembre, para la promoción de la igualdad de género en Andalucía; Ley 11/2016, de 28 de julio, de igualdad de mujeres y hombres de Baleares; Ley 1/2010, de 26 de febrero, canaria de igualdad entre mujeres y hombres; Ley 12/2010, de 18 de noviembre, de igualdad entre mujeres y hombres de Castilla-La Mancha; Ley 1/2003, de 3 de marzo, de igualdad de oportunidades entre mujeres y hombres en Castilla y León; Ley 17/2015, de 21 de julio, de igualdad efectiva de mujeres y hombres (Cataluña); Decreto Legislativo 2/2015, de 12 de febrero, por el que se aprueba el texto refundido de las disposiciones legales de la Comunidad Autónoma de Galicia en materia de igualdad; o, Ley 4/2005, de 18 de febrero, para la igualdad de mujeres y hombres (País Vasco). Aunque buena parte de las Comunidades Autónomas optan por regular de manera separada su marco regulatorio en materia de igualdad, otras Comunidades Autónomas lo hacen de manera conjunta con la regulación sobre violencia de género. A modo de ejemplo, es lo que hacen Asturias con la Ley 2/2011, de 11 de marzo, para la igualdad de mujeres y hombres y la erradicación de la violencia de género, Extremadura con la Ley 8/2011, de 23 de marzo, de igualdad entre mujeres y hombres y contra la violencia de género en Extremadura o Murcia mediante la Ley $7 / 2007$, de 4 de abril, para la igualdad entre mujeres y hombres y de protección contra la violencia de género en la Región de Murcia.

Precisamente sobre la normativa sobre violencia de género tanto en el marco estatal como autonómico, hace un riguroso análisis y valoración LÓPEZ BENÍTEZ, M. (2019): “Una aproximación a la normativa sobre violencia de género desde el derecho administrativo”, en Revista General de Derecho Administrativo, núm. 50. 
acaban de publicarse la Ley cántabra 2/2019, de 7 de marzo, que lleva por título idéntico nombre al de la norma estatal ${ }^{28}$ y la Ley foral $7 / 2019$, de 4 de abril, de igualdad entre mujeres y hombres de Navarra ${ }^{29}$.

El objeto de esta Ley es, precisamente, hacer efectivo el derecho de igualdad de trato y de oportunidades entre mujeres y hombres, en particular mediante la eliminación de la discriminación de la mujer, sea cual fuere su circunstancia o condición y en cualquiera de los ámbitos de la vida, singularmente, en las esferas política, civil, laboral, económica, social y cultural, con la meta de alcanzar una sociedad más democrática, más justa y más solidaria. Para ello, y al amparo de la atribución constitucional al Estado de la competencia para la regulación de las condiciones básicas que garanticen la igualdad de todos los españoles en el ejercicio de los derechos y en el cumplimiento de los deberes constitucionales (art. 149.1.1. ${ }^{\circ} \mathrm{CE}$ ) aunque, como reconoce expresamente, dedicando una regulación más detallada a aquellos ámbitos de competencia, básica o legislativa plena, del Estado, se promulga este cuerpo legal dirigido a la generalidad de las políticas públicas, tanto estatales como autonómicas y locales ${ }^{30}$.

Entre los instrumentos básicos que establece la Ley Orgánica 3/2007, en el ámbito de la Administración General del Estado, además de un Plan Estratégico de Igualdad de Oportunidades, la creación de una Comisión Interministerial de Igualdad con responsabilidades de coordinación o los informes y evaluaciones periódicos sobre la efectividad del principio de igualdad, también se establecen los informes de impacto de género regulados por el art. 19 y que obligan a incorporar este documento tanto a los proyectos de disposiciones de carácter general como a los planes de especial relevancia económica, social, cultural y artística que se sometan a la aprobación del Consejo de Ministros.

Por su parte, el art. 31 está dedicado precisamente a las políticas urbanas, de ordenación territorial y vivienda. El precepto establece que las políticas y planes de las Administraciones públicas en materia de acceso a la vivienda deben incluir medidas para hacer efectivo el principio de igualdad de trato entre mujeres y hombres, principio básico de la norma que enuncia en el art. 3 como aquel que «supone la ausencia de toda discriminación, directa o indirecta, por razón de sexo y, especialmente, las derivadas de la maternidad, la asunción de las obligaciones familiares y el estado civil». Igualmente, las políticas urbanas y de ordenación del territorio deben tomar en consideración las necesidades de los distintos grupos sociales y de los diversos tipos de estructuras familiares, y favorecer el acceso en condiciones de igualdad a los distintos servicios e infraestructuras urbanas. De manera singular, el aptdo. 3 del art. 31, se refiere a la inclusión de la perspectiva de género en el diseño de la ciudad, en las políticas urbanas, y en la definición y ejecución del planeamiento urbanístico para lo que aboga por el empleo de mecanismos e instrumentos que fomenten y favorezcan la participación y la transparencia. Sin embargo, no concreta cuáles hayan de ser esos mecanismos o instrumentos a los que hace referencia en sintonía con su propia exposición de motivos que, consciente del marco competencial, ya adelanta la intención de la Ley Orgánica 3/2007 de conjugar la competencia del art. 149.1.1. ${ }^{\circ}$ dirigida a establecer las condiciones básicas que garanticen la igualdad de todos los españoles con los ámbitos de competencia básica o legislativa plena del Estado. Por contra, sí apunta el marco en que han de desenvolverse, el de la participación ciudadana y la transparencia.

Profundizando en la inclusión de este principio en el marco de las políticas urbanas y territoriales desde la normativa estatal es referencia obligada el Real Decreto Legislativo 7/2015, de 30 de octubre, por el que se aprueba el texto refundido de la Ley de Suelo y Rehabilitación Urbana (TRLSRU) ${ }^{31}$. El TRLSRU acoge el principio de desarrollo territorial y urbano sostenible en su art. 3, estableciendo como fin común de las políticas públicas relativas a la regulación, ordenación, ocupación, transformación y uso del suelo, la utilización del mismo conforme al interés general y al principio de desarrollo sostenible. El principio de desarrollo territorial y urbano sostenible fija como objetivo general el «propiciar el uso racional de los recursos naturales armonizando los requerimientos de la economía, el empleo, la cohesión social, la igualdad de trato y de oportunidades, la salud y la seguridad de las personas y la protección del medio ambiente», pero también establece un mandato dirigido a los poderes públicos para que formulen y desarrollen en el medio urbano, las políticas de su competencia conforme a los principios de competitividad y sostenibilidad económica, so-

28 BOC extraordinario, núm. 5, de 08-03-2019.

29 BON, núm. 71, de 11-04-2019.

30 Sobre la aplicación y eficacia de la Ley Orgánica 3/2007, vid. VENTURA FRANCH, A. y GARCÍA CAMPÁ, S. (dirs.) (2018): El derecho a la igualdad efectiva de mujeres y hombres: una evaluación del primer decenio de la Ley Orgánica 3/2007. Navarra: Thomson Reuters Aranzadi.

31 Con anterioridad, la Ley 8/2007, de 28 de mayo, de Suelo, ya incorporaba en su art. 2 el principio de desarrollo territorial y urbano sostenible. 
REALA. Nueva Época - N.o 12, octubre-marzo 2019 - ISSN: 1989-8975 - DOI: 10.24965/reala.i12.10702 - [Págs. 52-71]

Urbanismo y género: del informe de impacto de género al principio de igualdad de trato como inspirador de la nueva concepción..

Esther Rando Burgos

cial y medioambiental, cohesión territorial, eficiencia energética y complejidad funcional, orientado hacia dos cuestiones concretas: un medio urbano «suficientemente dotado» y en el que "el suelo se ocupe de manera eficiente, combinando los usos de forma funcional».

Y en este contexto, el art. 3.3 del TRLSRU lo particulariza fijando cuestiones concretas para su materialización, entre otras, con acciones que aproximan el derecho de los ciudadanos, valga la redundancia, a la ciudad. Cuestiones como mejorar la calidad y la funcionalidad de las dotaciones, infraestructuras y espacios públicos al servicio de todos los ciudadanos y fomentar unos servicios generales más eficientes económica y ambientalmente; garantizar el acceso universal de los ciudadanos a los edificios de uso privado y público, y a las infraestructuras, dotaciones, equipamientos, transportes y servicios; integración en el tejido urbano de cuantos usos resulten compatibles con la función residencial para contribuir al equilibrio de las ciudades y de los núcleos residenciales, favoreciendo la diversidad de usos, la aproximación de los servicios, las dotaciones y los equipamientos a la comunidad residente, así como la cohesión y la integración social, son enumerados en el citado cuerpo legal. Y finaliza el TRLSRU, en el aptdo. 4 del propio art. 3, estableciendo un mandato para todos los poderes públicos dirigido a garantizar los derechos y deberes de los ciudadanos, así señala «Los poderes públicos promoverán las condiciones para que los derechos y deberes de los ciudadanos establecidos en los artículos siguientes sean reales y efectivos, adoptando las medidas de ordenación territorial y urbanística que procedan para asegurar un resultado equilibrado, favoreciendo o conteniendo, según proceda, los procesos de ocupación y transformación del suelo».

El derecho a la ciudad interrelacionado con el principio de igualdad tiene diferentes vertientes en las que se materializa, entre ellas, esencial, la igualdad de trato, pero parece adecuado entenderla desde una perspectiva más amplia y extensible al conjunto de la ciudadanía, entre las que se incluye, por supuesto, la igualdad efectiva entre hombre y mujeres. El propio TRLSRU al regular los «criterios básicos de utilización del suelo», en el art. 20, y precisamente, como señala el precepto, «para hacer efectivos los principios y los derechos y deberes enunciados en el título preliminar y en el título I, respectivamente, las Administraciones Públicas, y en particular las competentes en materia de ordenación territorial y urbanística, deberán», enumerando, entre otros, «atender, en la ordenación que hagan de los usos del suelo, a los principios de accesibilidad universal, de igualdad de trato y de oportunidades entre mujeres y hombres, de movilidad, de eficiencia energética, de garantía de suministro de agua, de prevención de riesgos naturales y de accidentes graves, de prevención y protección contra la contaminación y limitación de sus consecuencias para la salud o el medio ambiente» (art. 20.1.c) TRLSRU).

Cierto que se está ante principios inspiradores y la dificultad que conlleva su efectiva implementación. De ahí la importancia de avanzar en este sentido, camino en el que resulta esencial no sólo el paulatino reconocimiento en nuestro ordenamiento jurídico sino también y junto a aquél, la exigencia por nuestros órganos jurisdiccionales. Y en este sentido, el interés de la STS de 10 de diciembre de 2018 en tanto supone un «paso de gigantes» al fijar como doctrina jurisprudencial en su FD Decimosexto:

...el principio de igualdad de trato es un principio inspirador de la nueva concepción del desarrollo urbano, que exige una ordenación adecuada y dirigida, entre otros fines, a lograr la igualdad efectiva entre hombres y mujeres, esto es, no es necesario el sometimiento del plan a un trámite específico para que esa perspectiva sea tenida en cuenta y para que, en otro caso, el citado plan pueda ser impugnado y el control judicial alcanzar a dichos extremos.

Se está ante una cuestión que va mucho más allá de su «control» vía informe preceptivo en la tramitación de un instrumento. El principio de igualdad en cuanto derecho a la ciudad es una filosofía que debe imbricarse en los propios modelos urbanos o territoriales establecidos por los planes. Si los planes obvian que la ciudadanía es el elemento esencial para el que se fija un determinado modelo de futuro, la que está llamada a usarla, disfrutarla y desenvolverse en ella, y la diversidad consustancial a esa ciudadanía, se alejará de la meta y objetivo al que están llamados.

Y en este sentido, la STS de 10 de diciembre de 2018 contiene pronunciamientos de gran relevancia. Así reconoce, en el FD Decimocuarto, que «...el principio de igualdad de género no resulta una cuestión neutral en materia de urbanismo», apuntando como la Ley Orgánica 3/2007, de 22 de marzo, para la Igualdad Efectiva de Mujeres y Hombres, reconoce la transversalidad del principio de igualdad de trato entre hombre y mujeres, o el propio art. 2 de la Ley del Suelo de 2007 (hoy recogido por el art. 3.2 del TRLSRU) que, como se indicaba con anterioridad, en virtud del principio de desarrollo sostenible, las políticas públicas deben incorporar cuestiones como la igualdad de trato y de oportunidades. Sin obviar que, a diferencia de 
REALA. Nueva Época - N.o 12, octubre-marzo 2019 - ISSN: 1989-8975 - DOI: 10.24965/reala.i12.10702 - [Págs. 52-71]

Urbanismo y género: del informe de impacto de género al principio de igualdad de trato como inspirador de la nueva concepción..

Esther Rando Burgos

otros principios asociados al derecho territorial y urbano sostenible, en el caso del principio de igualdad de trato, la legislación estatal no incorpora ningún trámite específico para su concreción en el planeamiento urbanístico. A modo de ejemplo, el propio TRLSRU, en el art. 22 al regular la evaluación y seguimiento de la sostenibilidad del desarrollo urbano, señala el sometimiento de los instrumentos de ordenación territorial y urbanística a evaluación ambiental (aptdo. 1), o la emisión de determinados informes en la fase de consultas de los instrumentos de ordenación de actuaciones de urbanización, como el de la Administración hidrológica sobre la existencia de recursos hídricos necesarios para satisfacer las nuevas demandas y sobre la protección del dominio público hidráulico (art. 22.3.a) TRLSRU); el de la Administración de costas sobre el deslinde y la protección del dominio público marítimo-terrestre (art. 22.3.b) TRLSRU); o, el de las Administraciones competentes en materia de carreteras y demás infraestructuras afectadas, acerca de dicha afección y del impacto de la actuación sobre la capacidad de servicio de tales infraestructuras (art. 22.3.c) TRLSRU).

Sin embargo, la Sentencia va más allá y entiende lo que parece una cuestión de sentido común «...con independencia de los procedimientos específicos de elaboración de planes de urbanismo en cada una de las leyes autonómicas, las cuales pueden o no incorporar trámites específicos en materia de género, es lo cierto que el principio de igualdad de trato es un principio inspirador de la nueva concepción del desarrollo urbano, que exige una ordenación adecuada y dirigida, entre otros fines, a lograr la igualdad efectiva entre hombres y mujeres, esto es, no es necesario el sometimiento del plan a un trámite específico para que esa perspectiva sea tenida en cuenta y para que, en otro caso, el citado plan pueda ser impugnado y el control judicial alcanzar a dichos extremos». Con ello queda abierta la puerta a la impugnación de planes por vulneración del principio de igualdad de trato en los modelos urbanos planteados por los planes urbanísticos más allá de la cumplimentación de un trámite procedimental concreto, tal es la emisión del informe de impacto de género, reconociendo la enorme amplitud que esta cuestión engloba y que, insistimos, va mucho más allá de la inclusión de un documento en el procedimiento de elaboración del plan.

Sin embargo, hasta el momento, la inclusión de criterios o trámites específicos dirigidos a la concreción y consecución del principio de igualdad de trato en el planeamiento urbanístico por las leyes autonómicas suele, por lo general, quedar limitada a su enunciación como principios. Pero se avanza en ello, y empiezan paulatinamente a implantarse criterios concretos para su materialización efectiva en los planes urbanísticos y territoriales. Aunque de manera aún muy reciente y puntual, se aprecia una incipiente tendencia por parte de las legislaciones urbanísticas y en ordenación territorial hacia la materialización e implantación de manera efectiva en los instrumentos de este principio.

\subsection{Inclusión del principio de igualdad de trato por las legislaciones urbanísticas autonómicas}

Paulatinamente, diferentes Comunidades Autónomas han incorporado a las legislaciones urbanísticas el principio de desarrollo sostenible y dando un paso más allá, algunas han optado por incluir el principio de igualdad, afinando hacia la igualdad de trato e incluso la igualdad de oportunidades entre hombres y mujeres entre los principios y fines de la actividad urbanística. En este sentido, y sin carácter exhaustivo, Andalucía, Aragón, Castilla y León, Baleares o Extremadura.

Andalucía opta por fijar entre los fines de la actividad urbanística la integración del principio de igualdad consagrado en el art. 14 de la $\mathrm{CE}^{32}$ pero junto a aquél, señala como principio de la ordenación urbanística que se establezca en los instrumentos de planeamiento, el de promoción de la igualdad de género ${ }^{33}$.

Tanto Aragón ${ }^{34}$ como Baleares ${ }^{35}$ optan por incluir en sus correspondientes legislaciones urbanísticas el principio de desarrollo territorial y urbano sostenible, con una redacción casi literal a la prevista en TRLSRU, eso sí, en el marco de los principios inspiradores de la actividad urbanística.

De análoga forma, Extremadura enuncia como principio general de la ordenación territorial y urbanística «La igualdad de oportunidades entre mujeres y hombres, sin que pueda prevalecer desde el plano de la ordenación territorial discriminación de las personas con discapacidad o por razón alguna o circunstancia

32 Art. 3.1.h) de la Ley 7/2002, de 17 de diciembre, de Ordenación Urbanística de Andalucia (LOUA).

${ }_{33}$ Art. 3.2.i) de la LOUA.

${ }^{34}$ Aragón incorpora, entre los principios de la actividad urbanística, el desarrollo sostenible en el art. 3.a) del Decreto-Legislativo 1/2014, de 8 de julio, del Gobierno de Aragón, por el que se aprueba el texto refundido de la Ley de Urbanismo de Aragón.

${ }_{35}$ Baleares, al señalar las finalidades y atribuciones de la actividad urbanística, incorpora el principio de desarrollo sostenible, con una transcripción casi literal a la del art. 3 del TRLSRU, en el art. 3 de la Ley 1/2017, de 29 de diciembre, de Urbanismo de las Islas Baleares (LUIB). 
personal o social, entendiendo que la función pública y el interés general en una sociedad diversa se fundamentan en la atención específica de las necesidades diferenciadas» ${ }^{36}$. Mientras, Castilla y León incorpora de manera más general, también como objetivo de la actividad urbanística y en aplicación de los principios constitucionales de la política económica y social desarrollados en el marco estatal (se refiere a la Ley del Suelo de 2007), el principio de desarrollo sostenible, entre otros, "La igualdad de trato y de oportunidades para todas las personas, mediante el libre acceso a la información, el fomento de la participación social y la sensibilidad con las peculiaridades locales y los grupos sociales menos favorecidos» ${ }^{37}$.

Aunque también optan por incorporar estos principios como inspiradores de sus respectivos marcos legislativos, Canarias y Comunidad Valenciana van un paso más allá. En principio, Canarias, entre los principios que enumera, contempla el «desarrollo sostenible» conformado, entre otros, por «la intervención pública en relación con la ordenación del suelo deberá atender y respetar el principio universal de igualdad entre hombres y mujeres» ${ }^{38}$. También incorpora el interés general, la igualdad de género y la solidaridad intergeneracional al referirse a los «criterios de intervención» en relación a la ordenación de los recursos naturales ${ }^{39}$, así como el principio específico inspirador de la propia ley en relación con la ordenación territorial y urbanística «La promoción del uso racional de los recursos naturales y territoriales, armonizando las exigencias derivadas de su protección y conservación con el desarrollo económico, el empleo, la cohesión social, la igualdad de trato y de oportunidades entre hombres y mujeres y, en general, la mejora del nivel de vida de la ciudadanía, compensando de forma adecuada a quienes se comprometan a su costa con esos objetivos ${ }^{40}$. De manera más concreta, al regular los principios de ordenación del suelo, Canarias aboga por «...la ordenación de los usos del suelo deberá atender a los principios... de accesibilidad universal; de igualdad entre hombres y mujeres... ${ }^{41}$, incluyendo entre los criterios de ordenación territorial del archipiélago, la consecución de «la configuración de un territorio equilibrado, organizado en un conjunto de centralidades escalonadas que permitan el acceso de la ciudadanía a unos servicios eficientes y una mejor calidad de vida, la consolidación de unas ciudades más dinámicas, el desarrollo endógeno de las áreas rurales y una mejor y más diferenciada articulación entre el medio rural y el medio urbano, incorporando criterios de cercanía y disminuyendo las necesidades de movilidad, así como la consecución de la igualdad de oportunidades entre hombres y mujeres» ${ }^{42} 0$ «la igualdad de acceso a las infraestructuras, los equipamientos, el conocimiento y la información» ${ }^{43}$.

En este contexto, destacable, la Comunidad Valenciana, lo que se constata desde la propia concreción del objeto de la ley, al establecer como tal «...la regulación de la ordenación del territorio valenciano, de la actividad urbanística, de la utilización racional del suelo y de la conservación del medio natural, desde una perspectiva de género e inclusiva» (art. 1 de la LOTUPV). Y lo concreta al regular los "criterios de la ocupación racional del suelo», en particular, establece un conjunto de deberes a la planificación territorial y urbanística, como criterios generales de crecimiento territorial y urbano, dirigidos a procurar un desarrollo territorial y urbano sostenible que incorpore la perspectiva de género ${ }^{44}$. Pero además, incluye expresamente el principio de igualdad al regular la «cohesión social, perspectiva de género y urbanismo» ${ }^{45}$.

\subsection{Un paso más: de los principios inspiradores a la instrumentalización de la igualdad de trato en las legislaciones urbanísticas autonómicas}

Se avanza de manera paulatina pasando de la enunciación como principios a la materialización a través de concretas previsiones a incorporar en los instrumentos con la finalidad de conseguir una efectiva igualdad en las ciudades y territorios. En este escenario, es adecuado destacar algunas Comunidades Autónomas que vienen incorporando en sus legislaciones urbanísticas mecanismos concretos dirigidos hacia una efectiva y real consecución de lo que, en origen, se postula como principio.

\footnotetext{
${ }^{36}$ Art. 2.1.d) de la Ley 11/2018, de 21 de diciembre, de Ordenación Territorial y Urbanística Sostenible de Extremadura (LOTUSE).

37 Art. 4.b) $1^{\circ}$ ) de la Ley 5/1999, de 8 de abril, de Urbanismo de Castilla y León (LUCyL).

38 Art. 3.6 de la Ley 4/2017, de 13 de julio, del Suelo y de los Espacios Naturales Protegidos de Canarias (LSENPC).

39 Art. 4.1. de la LSENPC.

${ }^{40}$ Art. 5.2.a) de la LSENPC

${ }^{41}$ Art. 81.1 de la LSENPC.

42 Art. 82.a) de la LSENPC.

43 Art. 82.e) de la LSENPC.

${ }^{44}$ Art. 7.2 de la Ley 5/2014, de 25 de julio, de Ordenación del Territorio, Urbanismo y Paisaje de la Comunidad Valenciana (LO-

${ }^{45}$ Art. 13 , aptdos. 1 y 2 , de la LOTUPV.
} TUPV). 
REALA. Nueva Época - N.o 12, octubre-marzo 2019 - ISSN: 1989-8975 - DOI: 10.24965/reala.i12.10702 - [Págs. 52-71]

Urbanismo y género: del informe de impacto de género al principio de igualdad de trato como inspirador de la nueva concepción..

Esther Rando Burgos

Nuevamente sin carácter exhaustivo, nos detendremos en algunas previsiones concretas como las establecidas por Baleares, Canarias, Cataluña, Extremadura y Valencia. Como denominador común, todas han optado por la inclusión de cuestiones precisas destinadas a garantizar la igualdad de trato entre las determinaciones que deben incluir sus diferentes instrumentos, no sólo urbanísticos, en algunos casos, también de ordenación territorial.

\subsubsection{La memoria social de los planes urbanísticos}

Baleares implanta lo que denomina «memoria social del plan». Los planes generales, instrumento de planeamiento urbanístico dirigido a establecer la ordenación integral y de carácter estructural del territorio que planifica, se integra por diversos documentos, entre ellos, la memoria informativa y justificativa ${ }^{46}$. En este contexto, el art. 39 de la LUIB, al regular su contenido, establece en el aptdo. 3, la «memoria social del plan» que define como el documento «de evaluación y justificación de las determinaciones del plan relativas a las necesidades sociales de acceso a la vivienda, y también formará parte una evaluación del impacto de la ordenación urbanística propuesta en función del género, así como con respecto a los colectivos sociales que requieran atención específica, tales como las personas inmigrantes y las personas mayores, con el objeto de que las decisiones del planeamiento, a partir de la información sobre la realidad social, contribuyan al desarrollo de la igualdad de oportunidades entre mujeres y hombres, así como a favorecer a los otros colectivos merecedores de protección».

De manera similar, Cataluña incorpora la «memoria social», con la particularidad de pormenorizar el contenido concreto para evaluar el modelo urbanístico propuesto por el plan en función del género pero también atendiendo a otros colectivos merecedores de una especial atención. Ya la disposición adicional decimoctava del Decreto Legislativo 1/2010, de 3 de agosto, por el que se aprueba el texto refundido de la Ley de Urbanismo de Cataluña (TRLUC), señala la «incorporación de la perspectiva de género» en el desarrollo de la ley, y lo hace encomendando al Departamento de Política Territorial y Obras Públicas su incorporación en dos ámbitos, en la representación paritaria en la composición de los órganos urbanísticos colegiados y en la evaluación del impacto de la acción urbanística en función del género. Con esta atribución, es el Decreto 305/2006, de 18 de julio, por el que se aprueba el Reglamento de la Ley de Urbanismo, el que incorpora a una figura ya prevista en la propia ley, la «memoria social», ampliando el contenido atribuido a aquélla, la necesidad de evaluar el impacto de la ordenación urbanística propuesta en función del género, así como respecto a los colectivos sociales que requieren atención específica. Incorporada como documentación preceptiva en los planes de ordenación urbanística municipal, en concreto en la memoria, en la que se integra la «memoria social» ${ }^{47}$ que, entre otros, debe contener «una evaluación del impacto de la ordenación urbanística propuesta en función del género, así como respecto a los colectivos sociales que requieren atención específica, tales como los inmigrantes y la gente de la tercera edad, al objeto que las decisiones del planeamiento, a partir de la información sobre la realidad social contribuyan al desarrollo de la igualdad de oportunidades entre mujeres y hombres, así como favorecer a los otros colectivos merecedores de protección». Pero además, detalla el contenido que habrá de integrarla, en concreto:

- Una diagnosis de la situación a partir del análisis de la información sobre la población a la que afecta el plan, la identificación de los roles de género de los diferentes colectivos afectados, las necesidades de bienestar y estratégicas de mujeres y hombres y los otros colectivos en el ámbito.

- La valoración del impacto social y de género del plan, la cual comprende:

- La justificación de la coherencia de la ordenación propuesta con las necesidades detectadas de las mujeres y los hombres y de los otros colectivos en lo que concierne en especial a los parámetros de accesibilidad, movilidad, seguridad y uso del tejido urbano, teniendo en cuenta particularmente las necesidades de las personas que realizan las tareas de cuidado y gestión doméstica, así como de las que reciben esta atención.

- Medidas o determinaciones previstas en el plan que contribuyen al desarrollo de los objetivos de igualdad de oportunidades entre las mujeres y los hombres, así como entre los diversos grupos sociales.

\footnotetext{
46 Art. 38 de la LUIB.

47 Art. 69.5 del Reglamento de la Ley de Urbanismo de Cataluña.
} 
REALA. Nueva Época - N.o 12, octubre-marzo 2019 - ISSN: 1989-8975 - DOI: 10.24965/reala.i12.10702 - [Págs. 52-71]

Urbanismo y género: del informe de impacto de género al principio de igualdad de trato como inspirador de la nueva concepción..

Esther Rando Burgos

- Previsión de como incidirá la ordenación propuesta sobre la situación originaria de mujeres y hombres y de los otros colectivos.

\subsubsection{Determinaciones específicas en el contenido sustantivo de los planes}

En el caso de Canarias, se precisa la perspectiva de la igualdad de género como contenido sustantivo en dos instrumentos, uno de ordenación de los recursos naturales y del territorio (planes insulares de ordenación) y otro de ordenación urbanística (normas técnicas de planeamiento). Entre los criterios que han de fijar las normas técnicas de planeamiento se encuentran los relativos a la determinación de estándares mínimos de suelo para equipamientos y dotaciones en los que se incluya la perspectiva de la igualdad de género ${ }^{48}$. Para los planes insulares de ordenación, por su parte, se establece como contenido un diagnóstico que habrá de anteceder y que servirá para concretar las determinaciones de ordenación que han de integrarlo. Este diagnóstico territorial, ambiental y económico, analizará los recursos naturales, la población, con atención particular a la igualdad de género y el bienestar de las familias, así como al planeamiento vigente y la situación socioeconómica ${ }^{49}$.

También la Comunidad Valenciana, además de los criterios generales que establece para el planeamiento urbanístico y territorial, cuestión que será abordada en el apartado siguiente, fija concretas determinaciones que habrán de incluir algunos de estos instrumentos. A modo de ejemplo, el plan general estructural ${ }^{50}$, entre las determinaciones que debe integrar la ordenación estructural, incorpora el relativo a los «objetivos e indicadores de sostenibilidad, con perspectiva de género y de capacidad territorial... ${ }^{51}$, de igual forma, en la memoria informativa del documento ha de justificarse el cumplimiento de los objetivos de género ${ }^{52}$.

\subsubsection{Criterios y reglas para la planificación con perspectiva de género: la apuesta valenciana}

La Comunidad Valenciana avanza de manera significativa con la inclusión de criterios y reglas concretas para incluir de manera efectiva la perspectiva de género en el planeamiento urbanístico. Es con la reciente modificación de la LOTUPV, operada por la Ley $1 / 2019$, de 5 de febrero ${ }^{53}$, cuando la Comunidad Valenciana incorpora, además de los principios enunciados anteriormente, previsiones concretas dirigidas a su inclusión en el contenido de los planes así como criterios y reglas orientados a la consecución de lo que la ley denomina como «planificación con perspectiva de género».

El propio art. 13 LOTUPV, antes denominado «cohesión social y urbanismo», modifica su rúbrica por la de "cohesión social, perspectiva de género y urbanismo», lo que ya adelanta la importancia que se confiere a la perspectiva de género pero, además lo hace, incluyéndola con un aspecto tan interrelacionado como es la cohesión social. Este precepto obliga tanto a las políticas como a los planes urbanísticos y de ordenación territorial a incluir medidas para hacer efectivo el principio de igualdad entre las personas, y lo particulariza con la inclusión de la perspectiva de género en el diseño, definición y ejecución del planeamiento urbanísti$\mathrm{Co}^{54}$. Con dicho objetivo, remite a los criterios que enumera la ley en el anexo $\mathrm{X}^{55}$, pero además relaciona un conjunto de elementos que define como «claves» para su logro, centrados en cinco pilares: las relaciones de proximidad; la sostenibilidad; la ciudad cuidadora de las personas; el derecho de información y la participación ciudadana; y el uso del lenguaje inclusivo.

Lo que se ha de poner en debida relación con el anexo XII de la LOTUPV, dedicado expresamente a establecer los criterios y reglas para la planificación con perspectiva de género, definiendo parámetros objetivos para hacerlo efectivo en cada uno de los diez aspectos concretos que señala, tratando con ello de conjugar diferentes ámbitos transversales hacia un objetivo común. Así apuesta por la inclusión de la perspectiva de género en aspectos como: urbanismo para las personas, red de espacios comunes, proximidad

\footnotetext{
${ }^{48}$ Art. 141.1.c) de la LSENPC.

49 Art. 96.1 de la LSENPC.

50 Instrumento de planeamiento urbanístico y territorial de ámbito municipal, cuya función es establecer la ordenación estructural de uno o varios municipios completos.

51 Art. 21.1.a) de la LOTUPV.

52 Art. 34.1.a) de la LOTUPV.

53 Vigente desde el 08 de febrero de 2019

54 Art. 13.2 de la LOTUPV.

55 El anexo X de la LOTUPV establece los criterios y reglas para la planificación de las actuaciones de rehabilitación, regeneración y renovación urbanas.
} 
REALA. Nueva Época - N.o 12, octubre-marzo 2019 - ISSN: 1989-8975 - DOI: 10.24965/reala.i12.10702 - [Págs. 52-71]

Urbanismo y género: del informe de impacto de género al principio de igualdad de trato como inspirador de la nueva concepción..

Esther Rando Burgos

de las actividades de la vida cotidiana, combinación de usos y actividades, seguridad en el espacio público, habitabilidad del espacio público, equipamientos, vivienda, movilidad y transversalidad.

El «urbanismo para las personas» obliga a incluir en la memoria de los planes, programas y proyectos urbanísticos, un apartado con una caracterización cuantitativa (mediante técnicas de estudio demográficas y sociológicas, como pirámides de población, segregación por género, por edad, etc) y una caracterización cualitativa, a fin de identificar las necesidades y aspiraciones de la población afectada, estructurada por variables como edad, sexo y diversidad funcional.

Uno de los aspectos a los que se presta mayor atención es a la denominada «red de espacios comunes», con la que se señala la forma en que se define y conecta la red de espacios comunes que dan apoyo a las actividades diarias, «atendiendo especialmente a los desplazamientos de la vida reproductiva y de cuidados», constituida, entre otras, por espacios de relación (refiriéndose por tales a los jardines, plazas o calles); los equipamientos de uso diario destinados a la educación de las niñas y niños (las escuelas infantiles, centros para el cuidado o recreo de personas mayores, centros de salud, equipamientos deportivos...); los comercios y servicios cotidianos de productos básicos para la alimentación y el cuidado del hogar y del núcleo familiar; las paradas de transporte público; los viales que los comunican y conectan directamente; o, espacios para la gestión de residuos y reciclaje, mobiliario urbano, espacios para los animales de compañía, etc. Además de definir las cuestiones que integran la red de espacios comunes, fija el ámbito al que ha de atender la planificación para los mismos, el barrio o unidad morfológica y poblacional de características particulares, ámbitos que deben delimitarse en el plano de ordenación del plan de desarrollo urbanístico. La red de espacios comunes y los espacios públicos que conecta forman parte de la ordenación estructural de la red viaria.

También se atiende de manera precisa a aspectos como la «proximidad para la vida cotidiana», por ejemplo, fijando que todos los espacios de la red de espacios comunes se distribuyan con criterios de proximidad, entendiendo por tal la que permite el acceso a cada espacio desde una distancia máxima de diez minutos caminando o la disposición de «espacios de estar y de relación» vinculados a la red de peatones cada 300 metros; la «combinación de usos y actividades» (con un urbanismo inclusivo desde la perspectiva de género que combine usos, garantizando la inclusión de la totalidad de la población o la posibilidad de realización de actividades remuneradas en la vivienda); la "seguridad en el espacio público» (a modo de ejemplo, se apuesta por caminos escolares que fomenten la autonomía de movilidad de la infancia; la separación física de los carriles bici de los peatonales y del tráfico de vehículo a motor; incluso, la identificación de «sitios inseguros» para modificarlos y mejorarlos); la «habitabilidad del espacio público» (con espacios de peatones anchos, seguros y libres de conflictos con el tráfico de vehículos, incluso se fija que, como mínimo, el $75 \%$ de la superficie viaria que conforma la red de espacios para la vida cotidiana sean viales peatonales); los «equipamientos» (con reservas de suelo para la edificación de equipamientos y centros destinados a la atención de personas que necesiten espacios especializados como menores, personas mayores, personas con diversidad funcional o espacios para la inclusión social); "vivienda» (fomentando los diferentes tipos de viviendas que garanticen la combinación de usos y personas, atendiendo a los diferentes tipos de núcleos familiares, o la adaptación de las viviendas a «los ciclos evolutivos y vitales de quien los habite», así como favoreciendo «la vida reproductiva y personal»); o, la «movilidad» (favoreciendo cuestiones como el transporte público, la movilidad a pie y en bicicleta, que combina con otras más novedosas como la incorporación de la perspectiva de género en los planes de movilidad, atendiendo a diferentes situaciones de movilidad reducida o garantizando la seguridad en los itinerarios nocturnos mediante la iluminación adecuada y la ausencia de barreras físicas y visuales).

La última cuestión a la que atiende el anexo XII de la LOTUPV, viene referida propiamente a la "transversalidad», desde el entendimiento de que la implantación efectiva de la perspectiva de género en la práctica urbanística debe ser abordada de manera multiescalar, interdisciplinaria y participativa, para lo que plantea tres acciones:

- La perspectiva de género en la construcción y la gestión de la ciudad hay que desarrollarla en todas las escalas políticas, en todos los programas, planes y proyectos urbanísticos, desde la planificación hasta la gestión, desde la idea hasta su materialización, en acciones concretas que puedan ser percibidas y reconocidas por las personas a las que van dirigidas.

- La acción urbanística debe responder a las necesidades cotidianas y a la diversidad, y para hacerla efectiva es precisa la participación interactiva de profesionales de diferentes ciencias, sectores y procedencias, así como la participación de la ciudadanía, asegurando la paridad de mujeres y hombres. 
- En el marco del plan de participación pública56, hay que incorporar entre las personas interesadas en el proceso participativo, a los sectores de población correspondientes a los perfiles resultantes del análisis demográfico previsto por el propio anexo. Fomentando, especialmente, la participación de las mujeres en la elaboración de planes y proyectos urbanos con una doble función: incorporar al debate su forma de vivir la ciudad y disponer de su compleja visión formada desde la vinculación con otros grupos sociales que dependen de ellas, y que hace que su participación sea de especial interés en la ordenación del detalle de los planes y los proyectos de urbanización y de obra pública. Además, debe justificarse expresamente la participación de las personas de diferentes grupos sociales, los resultados de este estudio participativo y la incorporación a los documentos urbanísticos.

Sin duda, con la reciente modificación de la LOTUPV, la Comunidad Valenciana se instituye en un referente en el contexto comparado de las diferentes Comunidades Autónomas en la forma de establecer criterios y medidas concretas dirigidas al diseño de modelos urbanos y territoriales impregnados por el principio de igualdad de trato y en particular por la perspectiva de género que, además, de principio inspirador de estas políticas, pasa a tener la condición de determinaciones y contenido sustantivo en los instrumentos de obligada observancia en aquéllos.

\subsubsection{Los criterios de sostenibilidad y su concreción en la perspectiva de género: el reto extremeño}

El propio nombre de la recién promulgada Ley 11/2018, de 21 de diciembre, de Ordenación Territorial y Urbanística Sostenible de Extremadura ${ }^{57}$ (LOTUSE), ya anticipa su apuesta por la sostenibilidad. Su exposición de motivos adelanta la importancia que el texto confiere a la igualdad, particularizado en la perspectiva de género, desde el punto de vista del diseño de las ciudades, así señala «...el diseño de nuestras ciudades no es un diseño neutro, y el espectro de planificar las ciudades desde la perspectiva de género reconoce a aquellos grupos tradicionalmente olvidados a la hora de proyectar, aquellos conjuntos de personas de la sociedad considerados históricamente como "poco productivos económicamente" y, sin embargo, principales usuarios de nuestras ciudades, como lo son: la población infantil, las mujeres, las personas dependientes, las personas mayores, las personas con menos recursos, las personas con capacidades diversas... Es decir, si conseguimos dar visibilidad a estos colectivos, "ciudadanía de primera", conseguiremos diseñar ciudades para todas y todos y, en definitiva, ciudades inclusivas...».

Coherente con ello, la LOTUSE dedica su art. 10 a lo que denomina «criterios de ordenación sostenible», con los que viene a fijar criterios concretos con los que lograr la sostenibilidad territorial, medioambiental y cohesión social que propugna. Estos criterios los engloba en seis: sostenibilidad; movilidad y accesibilidad; conservación del patrimonio cultural; eficiencia energética; perspectiva de género; y, participación ciudadana.

El logro de un modelo urbano y territorial sostenible se alza en meta, superando con ello el propio principio de desarrollo territorial y urbano sostenible, conjugándose con otras metas estrechamente relacionadas con la misma, como la cohesión social o la propia vertebración del territorio. Y en este contexto, Extremadura determina los criterios concretos que posibiliten su logro pero además, y de manera particular, plantea acciones concretas dirigidas a la inclusión de criterios de sostenibilidad desde una perspectiva de género, en concreto cuatro:

- Los instrumentos de ordenación incorporarán en su análisis la perspectiva de género. A estos efectos deben incluir el denominado «mapa de riesgos» para el urbanismo desde la perspectiva de género con la localización de puntos, zonas o itinerarios considerados como «negros» para las mujeres y una propuesta de medidas para su corrección.

- Las determinaciones de los planes y la ordenación urbana están llamados a fomentar el libre movimiento de las personas mediante el diseño de espacios y conexiones seguros.

- El estudio de movilidad debe incluir planos de escala y detalle adecuado con trayectos y conexiones a las principales dotaciones, entre ellas centros docentes y asistenciales. Así mismo ha de detallar las características del transporte público, incluidas entre ellas sus frecuencias y horarios.

- A nivel organizativo, también se apuesta por procurar la representación paritaria en la composición de los órganos urbanísticos colegiados.

56 Previsto en el art. 53.1 y el anexo I de la LOTUPV.

57 Publicada en el DOE, núm. 250, de 27-12-2018, cuya disposición final segunda, pospone su entrada en vigor a los seis meses de su publicación en el DOE. Vigente desde el 27 de junio de 2019. 
REALA. Nueva Época - N.o 12, octubre-marzo 2019 - ISSN: 1989-8975 - DOI: 10.24965/reala.i12.10702 - [Págs. 52-71]

Urbanismo y género: del informe de impacto de género al principio de igualdad de trato como inspirador de la nueva concepción..

Esther Rando Burgos

Particular relevancia, por su novedad, el «mapa de riesgos para el urbanismo desde la perspectiva de género». Aspectos como la escasa iluminación nocturna, la dificultad del tránsito peatonal, incluso, el excesivo follaje de los árboles, a menudo desapercibidos, pueden llevar a determinadas zonas a ser poco propicias para el tránsito no sólo de mujeres, también de niños o de personas de mayor edad.

\section{REFLEXIONES FINALES}

El logro de modelos urbanos y territoriales sostenibles parece que, por fin, muestra signos que evidencian avances hacia su materialización, pasando del principio de desarrollo territorial y urbano sostenible al establecimiento de criterios y mecanismos concretos en algunos marcos legislativos autonómicos en urbanismo para alcanzarlo.

Pero bajo la generalidad de desarrollo urbano sostenible se cobijan diferentes cuestiones de tal envergadura que empiezan a tener su propio espacio en estos marcos legislativos. Aspectos como la cohesión social, la vertebración, la intermodalidad, la salud, la economía, el empleo u otros tantos, cada vez están más presentes en los mismos. Junto a ellos, una cuestión muy singular como el principio de igualdad de trato que aun englobado conjuntamente requiere, por su entidad, especial atención, en la medida en que se está ante un principio constitucionalmente reconocido con carácter de derecho fundamental y no ante una de otras tantas políticas públicas que inciden de manera más o menos directa en la configuración de nuestras ciudades.

Este principio de igualdad, en el marco del desarrollo sostenible, parece evidenciar el tránsito de una igualdad en sentido formal a una igualdad material o efectiva, en sus diversas manifestaciones, entre ellas, la igualdad de género. Se ha pasado del debate en torno a la necesidad de incluir trámites procedimentales específicos en los planes urbanísticos o territoriales, a través del informe de impacto de género y las consecuencias jurídicas de su omisión (con el referente de los casos analizados en el plan territorial de la Costa del Sol o el plan urbanístico de Boadilla del Monte) fruto de su carácter preceptivo en el procedimiento de tramitación y la doctrina jurisprudencial que sostiene el carácter reglamentario de los planes, al reconocimiento expreso por el propio Tribunal Supremo que, por primera vez, se refiere al derecho a la ciudad y en particular fija doctrina reconociendo que «el principio de igualdad de trato es un principio inspirador de la nueva concepción del desarrollo urbano, que exige una ordenación adecuada y dirigida, entre otros fines, a lograr la igualdad efectiva entre hombres y mujeres», superando el propio debate sobre la necesidad o no de establecer un informe y extendiéndolo mucho más allá hacia una forma de hacer ciudad, con la definición de modelos impregnados por el principio de igualdad de trato e incluso abriendo la puerta a que la omisión de este mandato, por sí mismo, pueda ser objeto de impugnación y del consiguiente control judicial.

Pero además, abundando en esta idea, se observa como paulatinamente por parte de las legislaciones urbanísticas se comienza a pasar del reconocimiento del principio a la concreción y exigencia mediante el establecimiento de criterios y mecanismos concretos que impregnan una concepción más global y transversal del principio de igualdad en los modelos que a definir.

Aunque el camino es largo y el logro complejo, anima comprobar que estamos asistiendo a una efectiva implementación en los marcos legislativos de modelos urbanos que deberán incorporar una verdadera y efectiva igualdad de trato entre el conjunto de la ciudadanía con independencia de las posibles singularidades que la misma presente en su vida en la ciudad y de manera singular atendiendo a una de sus vertientes, la igualdad de género.

\section{BIBLIOGRAFÍA}

ASAMBLEA GENERAL DE NACIONES UNIDAS (2015): Transformar nuestro mundo: la Agenda 2030 para el Desarrollo Sostenible. Resolución aprobada por la Asamblea General el 25 de septiembre de 2015, A/RES/70/1. Septuagésimo período de sesiones. Temas 15 y 116 del programa. URL: https://unctad.org/meetings/es/ SessionalDocuments/ares70d1_es.pdf.

BAÑO LEÓN, J. M. (2016): "Reconsideración sobre el régimen de impugnación del plan urbanístico", en GIFREU I FONT, J., BASSOLS COMA, M. y MENÉNDEZ REXACH, A. (dirs.): El derecho de la ciudad y el territorio: estudios en homenaje a Manuel Ballbé Prunés, págs. 859-871. Madrid: Instituto Nacional de Administración Pública, INAP.

BAÑO LEÓN, J. M. (2017): “El plan urbanístico en ruina: un esbozo de reconstrucción”, en Práctica Urbanística, núm. 144. 
REALA. Nueva Época - N.o 12, octubre-marzo 2019 - ISSN: 1989-8975 - DOI: 10.24965/reala.i12.10702 - [Págs. 52-71]

Urbanismo y género: del informe de impacto de género al principio de igualdad de trato como inspirador de la nueva concepción..

Esther Rando Burgos

BAÑO LEÓN, J. M. (2017): “Un plan jurídico de reforma para los planes urbanísticos”, en Revista de Derecho Urbanístico y Medio Ambiente, núm. 311, págs. 43-56.

BASSOLS COMA, M. (2017): "La asimilación de los planes de urbanismo a normas reglamentarias y problemática jurídica de su anulación”, en SORIA MARTÍNEZ, G. y BASSOLS COMA, M. (coords.): Los efectos de la nulidad de los instrumentos de planeamiento urbanístico, págs. 27-102. Navarra: Thomson Reuters Aranzadi.

FUERTES LÓPEZ, M. (2017): "Sentencias que anulan planes urbanísticos", en El blog de esPublico. Mejor blog nacional público. URL: https://www.administracionpublica.com/sentencias-que-anulan-planes-urbanisticos/\#.

GONZÁLEZ SANFIEL, A. M. (2017): "Límites a la declaración de nulidad del planeamiento", en LÓPEZ RAMÓN, F. y VILLAR ROJAS, F. J. (coords.): El alcance de la invalidez de la actuación administrativa: Actas del XII Congreso de la Asociación Española de Profesores de Derecho Administrativo, págs. 411-459. Madrid: Instituto Nacional de Administración Pública, INAP.

GONZÁLEZ SANFIEL, A. M. (2018): "Nulidad del planeamiento urbanístico e invalidez de los actos amparados en el mismo. Atención especial a las nuevas iniciativas legislativas al respecto", en Documentación Administrativa. Nueva Época, núm. 5, págs. 46-68. DOI: https://doi.org/10.24965/da.v0i5.10607.

GUTIÉRREZ COLOMINA, V. (2016): "Los efectos de la nulidad de los planes urbanísticos en Andalucía y su repercusión en las edificaciones ilegales”, en Revista Andaluza de Administración Pública, núm. 96, págs. 47-84.

HABITAT INTERNATIONAL COALITION (2012): "Carta Mundial por el Derecho a la Ciudad", en Revista de Paz y Conflictos, núm. 5, págs. 184-196.

LEFEBVRE, H. y GAVIRIA, M. (1969): El derecho a la ciudad. Barcelona: Península.

LÓPEZ BENÍTEZ, M. (2019): "Una aproximación a la normativa sobre violencia de género desde el derecho administrativo", en Revista General de Derecho Administrativo, núm. 50.

LORA-TAMAYO VALLVÉ, M. (2006): Derecho urbanístico y medio ambiente: hacia el desarrollo urbano sostenible. Madrid: Dykinson.

MOLANO CAMARGO, F. (2016): "El derecho a la ciudad: de Henri Lefebvre a los análisis sobre la ciudad capitalista contemporánea”, en Folios: Revista de la Facultad de Humanidades, núm. 44, págs. 3-19. DOI: https://doi.org/10. 17227/01234870.44folios3.19.

PÉREZ DEL PRADO, D. (2018): "Una aproximación a los indicadores de cumplimiento de los ODS desde la perspectiva de género", en Revista de Información Laboral, núm. 17, págs. 175-194.

RAMOS MEDRANO, J. A. (2017): "Más de 90 planes de urbanismo anulados judicialmente por no justificar la disponibilidad de los recursos hídricos", en Actualidad Jurídica Ambiental, núm. 67.

RAMOS MEDRANO, J. A. (2017): "Más de 90 planes de urbanismo anulados judicialmente por no realizar la Evaluación Ambiental Estratégica (EAE)", en Actualidad Jurídica Ambiental, núm. 73.

RANDO BURGOS, E. (2016): "La relevancia del procedimiento de tramitación de los instrumentos de planificación territorial: la nulidad del Plan de Ordenación del Territorio de la Costa del Sol de Málaga por la Sentencia del Tribunal Supremo de 6 de noviembre de 2015", en Actas VII Congreso Internacional de Ordenación del Territorio: nuevos tiempos, nuevos objetivos. Fuerteventura, 25, 26 y 27 de mayo de 2016, págs. 925-936. Asociación Interprofesional de Ordenación del Territorio, FUNDICOT.

RANDO BURGOS, E. (2018): "La anulación del Plan de Protección del Corredor Litoral de Andalucía por el Tribunal Superior de Justicia de Andalucia: ¿nuevas dificultades en la planificación territorial de Andalucía?”, en Revista de Estudios de la Administración Local y Autonómica, REALA. Nueva Época, núm. 10, págs. 109-131. DOI: https:// doi.org/10.24965/reala.v0i10.10518.

RANDO BURGOS, E. (s. f.): Régimen Jurídico de la Gestión Territorial. Tirant lo Blanch, en prensa.

REBOLLO PUIG, M. (2017): "Relaciones entre el ordenamiento estatal y los autonómicos", en REBOLLO PUIG, M. y VERA JURADO, D. J. (dirs.): Derecho Administrativo, Vol. I: Conceptos Fundamentales, Fuentes y Organización. Madrid: Tecnos.

RENAU FAUBELL, F. (2016): "La nulidad «radioactiva» de los planes urbanísticos por defectos en el procedimiento de aprobación", en Noticias Jurídicas, artículos doctrinales. URL: http://noticias.juridicas.com/conocimiento/articulosdoctrinales/10946-la-nulidad-Idquo;radioactivardquo;-de-los-planes-urbanisticos-por-defectos-en-el-procedimientode-aprobacion/.

SANTAMARÍA PASTOR, J. A. (2016): "Una imprevista disfunción del sistema urbanístico: la mortalidad judicial de los planes”, en Práctica Urbanística, núm. 141.

VENTURA FRANCH, A. y GARCÍA CAMPÁ, S. (dirs.) (2018): El derecho a la igualdad efectiva de mujeres y hombres: una evaluación del primer decenio de la Ley Orgánica 3/2007. Navarra: Thomson Reuters Aranzadi. 